\title{
SURVEY ON ADAPTATIONS OF BASKETBALL FOR PEOPLE WITH DISABILITIES
}

\author{
M. Aleksieva, S. Denev \\ University of Veliko Tarnovo St. Cyril and St. Methodius, Bulgaria
}

\begin{abstract}
Adapted physical activity is part of the physical activity in the present-day world. It uses a variety of physical exercises and sports as means of education, good upbringing, improvement and fulfilling life. The aim of adapted physical activity is to provide every person with the opportunity for social communication throughout their lives through physical activity as a preventive measure against the aggravation and complication of their illnesses.

This study aims to collect information on the knowledge of the rules of adaptations of the basketball game for people with specific needs.

The object of the study are the adaptations of the basketball game.

The scope of the study is the knowledge of the experts surveyed regarding the adaptations of the basketball game for people with disabilities.

The respondents for the research are 92 teachers and physical education experts, basketball coaches, physical education lecturers at higher education institutions with an interest in physical activity and basketball.

After processing the data, it is clear that participants in the survey do not know the rules of basketball game adaptations but strongly state their motivation to participate in training seminars on the four adaptations of basketball.
\end{abstract}

Key words: adapted physical activity, physical education, teachers, coaches

\section{INTRODUCTION}

The four pillars of modern education, according to a report to UNESCO of the International Commission on Education for the Twenty-first Century (1996: 85) "Learning: The Treasure Within" are:

1. Learning to know - this is general education in a broad sense or the in-depth knowledge of certain subjects. Combining them serves as a basis for improving lifelong learning.

2. Learning to do - these are the skills necessary to do a job or to deal with diverse situations and to work in a team, that is, opportunities to apply our own strategies in a variety of situations in the absence of a strictly defined scheme.

3. Learning to be - education that seeks to form personal qualities such as independence, personal responsibility and talents - memory, intellectual abilities, imagination, physical skills, aesthetic taste and communication skills. The goal is that everyone makes the best decisions in different situations and develops and deploys independently the full range of their personality.

4. Learning to live together - this is an education for understanding others and their history, traditions and values. It includes working on common projects and solving conflicts peacefully, that is tolerance and accepting the different.

For people with disabilities (mental or physical), some of these pillars are missing or violated. This leads to a deficiency in the fullness of their social life - in particular in the ability to reveal their physical skills.

Adapted physical activity is part of the physical activity in the present-day world. It uses a variety of physical exercises and sports as a means of education, upbringing, improvement and achieving a fulfilling life. Its purpose is to provide the opportunity for social communication of every person throughout his 
or her life through physical activity as a preventive measure against the deepening and complication of their illnesses. It is used as a means of treatment, sport, social rehabilitation or expression. Its main role is to prevent disability-related hypokinesia and social exclusion.

Adapted physical activity together with adapted sports are one of the most powerful factors for improving the quality of life and social integration of people with disabilities (2).

M. Gecheva conducted a study on the motivation and attitude of the students involved in systematic basketball activities, in the training process, on the support of their classmates, friends and parents, as well as the benefits of this employment (1). Her study shows that the respondents receive their parents' support for participating in an organised basketball training course.

The opportunities of sport and physical recreation for all people with disabilities are a very important tool for improving the quality of life, providing opportunities for enjoyable experiences and satisfaction that contribute to their rehabilitation and integration into society and includes sport in all its forms.

\section{PURPOSE}

The purpose of this study is to collect information on the knowledge of the rules of adaptations of the basketball game for people with disabilities by physical education teachers, basketball coaches, sports experts and high school lecturers as well as their motivation to participate the training process with people with special needs.

In order to accomplish the purpose, the following tasks were set:

1. Development of a questionnaire.

2. Conducting a poll with teachers and physical education and sports experts, basketball coaches, physical education and sports lecturers in higher education institutions with an interest in the adapted physical activity and the basketball game.

3. Summarising and analysing the results obtained.

4. Making conclusions and recommendations for practice.

\section{RESEARCH METHODOLOGY}

This research was conducted from $1^{\text {st }}$ to $5^{\text {th }}$ of April 2019.
The object of the research are the adaptations of the basketball game.

The scope of the research is the knowledge of the experts surveyed regarding the adaptations of the basketball game for people with special needs.

The respondents of the research are 92 teachers and physical education and sports experts, basketball coaches, physical education teachers and sports at higher education institutions with an interest in physical activity and basketball.

The following methods have been implemented to achieve the goal pursued and the objectives of the research:

An extensive analysis of specialised literature and a survey method.

In order to study the opinion of teachers and experts in physical education and sports, basketball coaches, physical education and sports lecturers in higher education institutions with interests in the field of physical activity and basketball, a survey was conducted. The questionnaire was anonymous and voluntary. It was provided in an electronic version to 105 teachers and experts in physical education and sports, basketball coaches, physical education and sports lecturers in higher schools in Bulgaria. They were all employed.

Between $1^{\text {st }}$ and $5^{\text {th }}$ of April 2019, 92 completed questionnaires were received.

The results of the survey were processed using a frequency analysis - for the ordering of the variables on their frequencies, performed with SPSS-19.

In the analysis of the questionnaire, the sequence of questions was not followed.

The developed questionnaire includes ten questions, divided in three parts:

- questions related to the age and the sex of the respondents;

- questions related to the knowledge of the rules of adaptations of the basketball game for people with disabilities;

- questions related to the motivation of the respondents to participate in the training process with people with special needs.

\section{RESULTS ANALYSIS}

The results of responses to age-related questions of respondents show the following: the majority are men - 54\% (Figure 1). Most respondents in the age range of 35-50 years 40 or $44 \%$, which speaks of mature age and 
respectively of serious experience in the respondents (Figure 2).

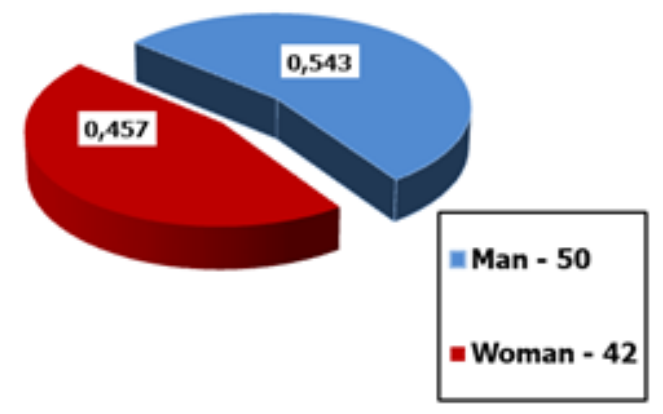

Figure 1. Sex

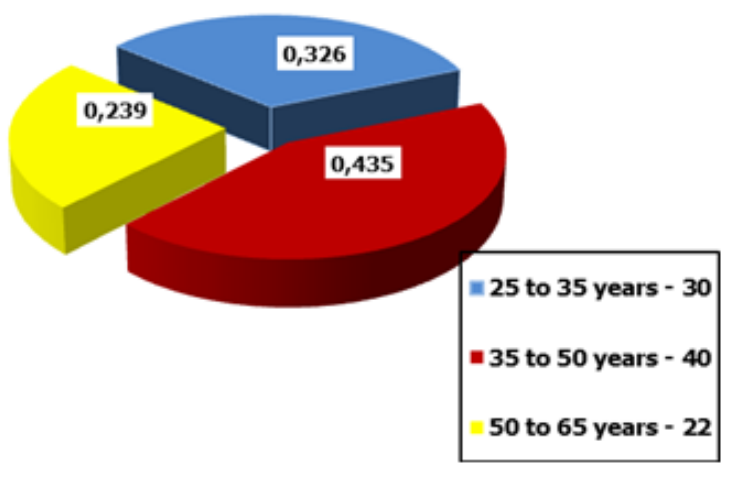

Figure 2. Age

The next group of questions with numbers 2,3 , 4 and 5 is related to the knowledge of the rules of adaptations of the basketball game for people with disabilities.

Of a great interest for the study is the answer to the question "Do you know the rules of basketball for people with disabilities?", given the popularity of classic basketball and the place it takes in the curriculum of physical education and sport (beginning in the primary level of the education system). Although the rules of basketball for people with disabilities are very close to the classical one, they also have specific features (Figure 3).

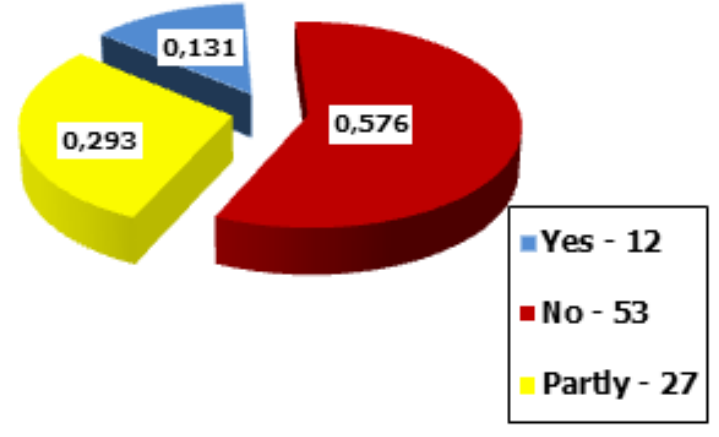

Figure 3. Do you know the rules of basketball for people with disabilities?
The most responses are negative - 53 answers or $58 \%$. 12 respondents have chosen the answer 'yes' has chosen, the answer "partly" $29 \%$. Respondents who have chosen the last answer most likely prefer it because they know the rules of classic basketball but are not aware of the specific rules of his adaptations for people with special needs.

Although the unified basketball has been developed by "Special Olympics Bulgaria" for more than 15 years, the participants in the survey are still not aware of its rules.

In this aspect of interpretation belong as well the answers to the next question "Do you know the rules of 3 vs 3 basketball for people with disabilities?" (Figure 4) If we take the youth tournament during the Asian Games held in Macau in November 2007 as the start of 3 vs 3 basketball, and the Asian Games for boys and girls in Singapore as the first official tournament, this type of basketball can definitely be defined as a very young sport. That is why the large percentage of respondents who have chosen the answer 'no' (59) and the small number of respondents one who have chosen 'yes' (4) is quite logical.

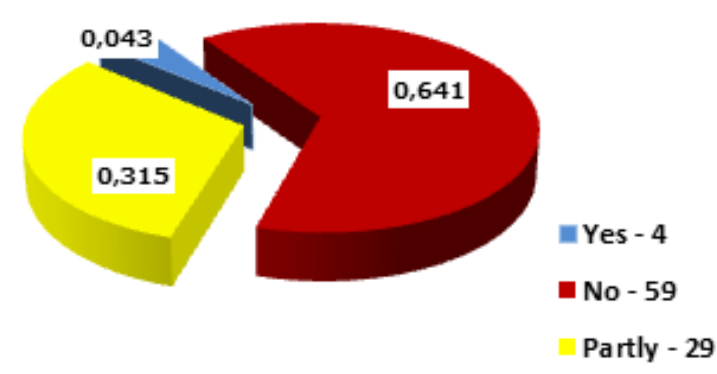

Figure 4. Do you know the rules of 3 vs 3 basketball for people with disabilities?

Perplexity arouses from the discrepancy in the "partly" answer of the two analysed questions 27 or $29 \%$ for basketball 5 vs 5 and 29 or $32 \%$ for $3 \mathrm{vs} 3$, i.e. respondents are better acquainted with the specifics of 3 vs 3 basketball for people with special needs than with the rules of unified basketball.

The popularity of wheelchair basketball among respondents is undeniable. 13 of them or $14 \%$ explicitly choose yes, and 26 or $28 \%$ - "partly" on the question "Do you know the rules of wheelchair basketball?", which shows that this type of basketball is recognisable to the respondents. Given that it is one of the most practiced sports by people with disabilities, and according to unofficial statistics, more 
than 100,000 people practice basketball with wheelchairs for entertainment, to be in a good shape as well as professionally, it is clear that many respondents know its rules. Another positive factor in support of this statement is the purposeful work of a team of lecturers from the NSA "V. Levski "- Professor Kr. Tsarov, Prof. R. Tsarova, Marin Vutov and Vl. Iskrov with the support of the Bulgarian Basketball Federation and Rotary Club, who created a non-profit association in 2007 - basketball club for people in wheelchairs "Sofia-Balkan". Training seminars for judges for wheelchair basketball in the years 2007 to 2018 also have an influence on the awareness of the rules of the game.

Totally Integrated Basketball is an adapted version of the basketball game, also suitable for athletes with mental disabilities, and for people in wheelchairs. This is also a new adapted activity for people with specific needs, again using the means of basketball (Figure 5).

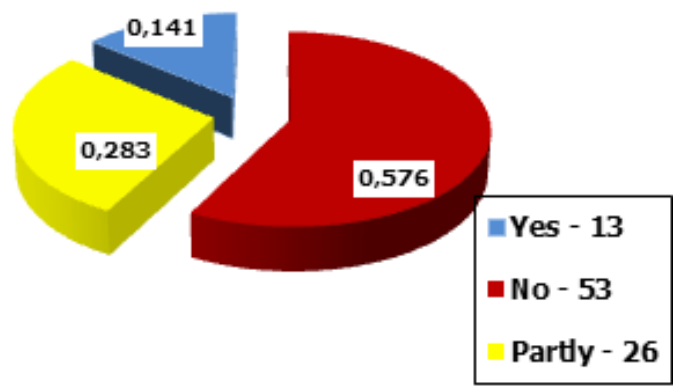

Figure 5. Do you know the rules of wheelchair basketball?

The largest is the number of respondents who have chosen the "no" answer to the question "Do you know the rules of T. In. BASKET? 73 or $79 \%$ (Figure 6). Compared with the previous questions related to the knowledge of the rules of other adaptations of basketball game this answer has the highest percentage of "no" answer.

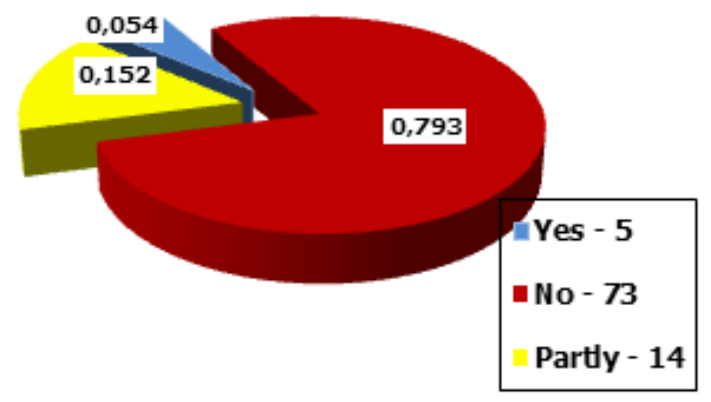

Figure 6. Do you know the rules of T. In. BASKET?

Questions 7,8 and 9 provide information on motivating respondents to participate in courses and in the training process with people with specific needs.

The respondents show an increased motivation to take part in training - $78 \%$ of them respond that they would participate in seminars to learn about the specifics of training of the listed adaptations of basketball. Six of them chose the answer "no" and eight cannot categorically answer the question "Would you take part in seminars to learn about the specifics of training of the listed adaptations of sports basketball?"(Figure 7).

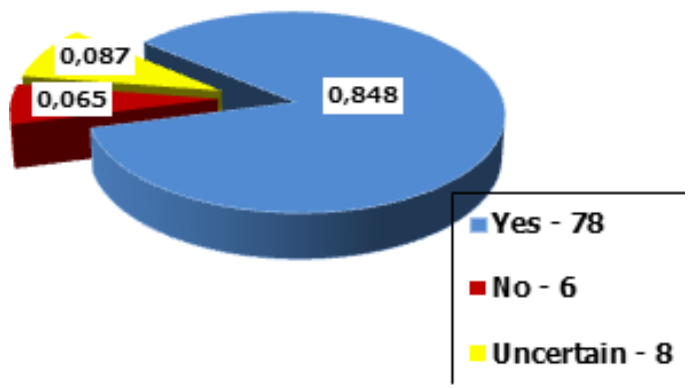

Figure 7. Would you take part in seminars to learn about the specifics of training of the listed adaptations of sports basketball?

Also interesting are the answers to the question "Would you take part in competitions or trainings as a volunteer in any of the basketball adaptations listed above?" Improvin the quality of life of people with special needs, trying to help them without financial gain just for the sake of satisfaction, is the foundation of volunteering. The high percentage (71) of respondents, who have chosen the 'yes' answer, is worthy of respect (Figure 8).

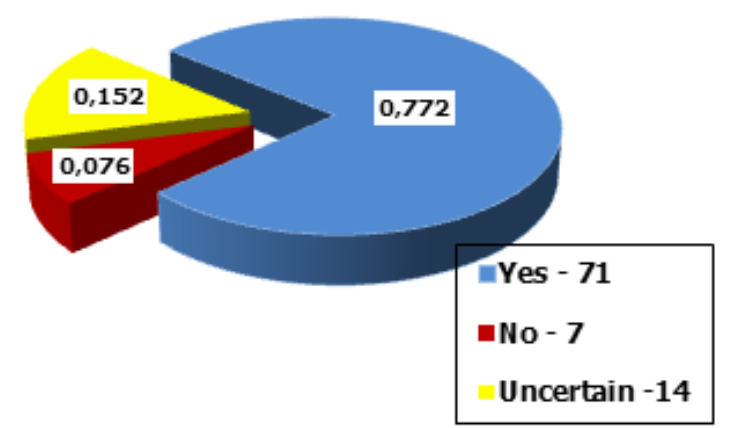

Figure 8. Would you take part in competitions or trainings as a volunteer in any of the basketball adaptations listed above?

However, this motivation could hardly find a correlation with the answers given to the next question "Would you like to be a coach in any of the basketball adaptations listed above?" As shown in Figure 10, 41 of the respondents 
did not demonstrate readiness to be coaches of people with special needs on any of the adaptations of the basketball game. This again confirms the difficulty that arises not only from the specific rules of adaptations but also from the lack of knowledge of the specifics of the training process with people with special needs.

This statement is logical given the answers to the question "Have you participated in a training process with people with special needs (regardless of the type of sport)?" They are illustrated in Figure 9, which shows that only 38 of the 92 respondents were involved in a training process with people with special needs. The specificity of the work, the difficulties that arise from it such as lack of suitable conditions, training methods, trained staff, support, support materials, etc., prove to be a serious barrier to engaging specialists to work with such a contingent of people.

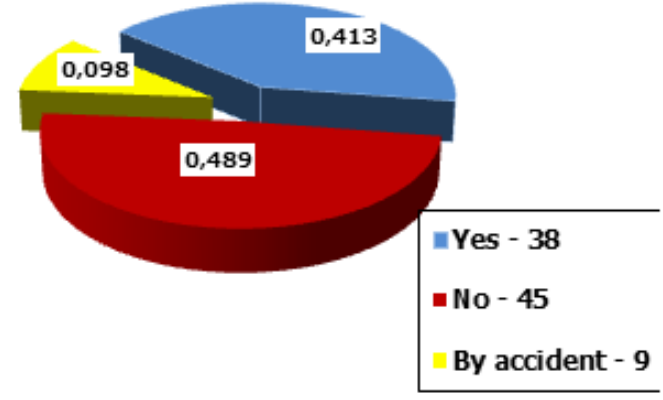

Figure 9. Have you participated in a training process with people with special needs (regardless of the type of sport)?

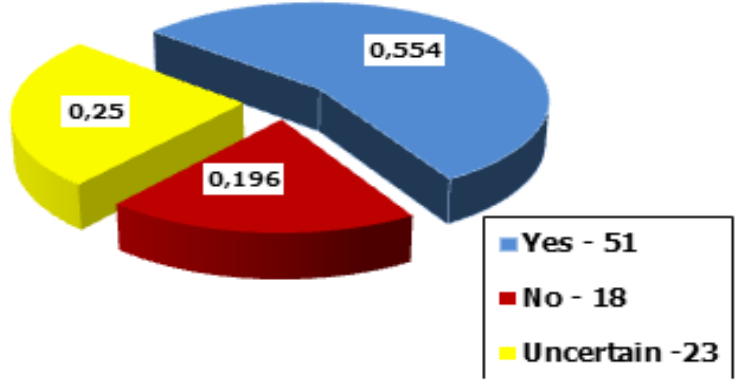

Figure 10. "Would you like to be a coach in any of the basketball adaptations listed above?"

\section{CONCLUSIONS}

1. Most of the participants in the survey do not know the rules of adaptations of the basketball game.

2. The respondents strongly state their motivation to participate in training seminars on the four adaptations of basketball.

3 . The respondents declare their willingness to participate as volunteers in competitions or training on any of the adaptations of the game.

4. Almost equal is their willingness to dedicate themselves to working with people with disabilities, applying one of the adaptations.

\section{RECOMMENDATIONS}

1. The results of the survey should be brought to the attention of interested parties.

2. Materials relating to the adaptations of the basketball game to be made available to all those willing to promote the rules and the possibilities for organising a training process.

3. Training seminars on the rules of the proposed adaptations of basketball game and the specifics of training and working with people with special needs should be organised. 4. Festivals and tournaments on the adapted versions of the basketball game should be organised in order to promote them and improve the quality of life of the participants.

\section{REFERENCES}

1. Gecheva, M. Study of the motivation and attitudes of students, parents and teachers and participation in the basketball training course. // "Modern Trends in Physical Education and Sports", University Press "St. Kliment Ohridski ", p.108, 2015.

2. Dimitrova-Belomazheva, St., St. Denev, M. Aleksieva. Adapted Physical Activity. V. Tarnovo: "A \& B", p. 8, 2016. 